Production Engineering Research and Development manuscript No.

(will be inserted by the editor)

\title{
In-line monitoring of carbon nanoparticle epoxy dispersion processes
}

\section{Insights into the process via next generation three roll mills and impedance spectroscopy}

\author{
H. Meeuw ${ }^{\text {a,* }}$. V. K. Wisniewski ${ }^{a}$. U. Köpke ${ }^{b}$ \\ A.S. Niac . A. R. Vázquez ${ }^{c}$ M. R. Lohe ${ }^{c}$ X. Feng ${ }^{c}$ \\ B. Fiedler ${ }^{\mathrm{a}}$
}

Received: date / Accepted: date

\begin{abstract}
The new generation of three roll mills (TRM) is able to monitor occurring process loads while dispersion. This paper focuses on the interpretation of the gathered data to find criteria quantifying the dispersion state online. The aim is process time reduction. We used impedance spectroscopy to identify the dispersion state and correlated it with the occurring process loads. The dispersion process of a wide spectrum of carbon based nano particles, namely carbon black (CB), single walled carbon nanotubes (SWCNT), multi walled carbon nanotubes (MWCNT), a few-layer graphene powder (FLG), electrochemically exfoliated graphite (ExG) and a functionalized electrochemically exfoliated graphite (fExG) was investigated. The filler content was varied along the material's electrical percolation threshold. The criteria found led to a reduction of processing time and revealed the prevalent mechanisms during dispersion.
\end{abstract}

Keywords carbon nano particle $\cdot$ dispersion $\cdot$ three roll mill

\section{Introduction}

The addition of conductive fillers like metal particles, carbon black, graphite or carbon fibers is a common method to introduce an electrical conductivity in intrinsically isolating polymers. The necessary filler content, depending on particle type, usually lays in the range of 5 to $15 \mathrm{wt} \%$. This high filler loadings hava a significant detrimental impact on the processing properties. Especially the viscosity increases with increased filler content [1,2]. Additionally, high concentrations of filler have a negative impact on the the mechanical properties [3] as well as chemical resistance, where low filler loadings are fovorable [4,5]. Further more a customization of the products is limited with regard to coloring. In the past the addition of carbon-based nano-particles was intensively investigated as an economic alternative [6]. The electrical

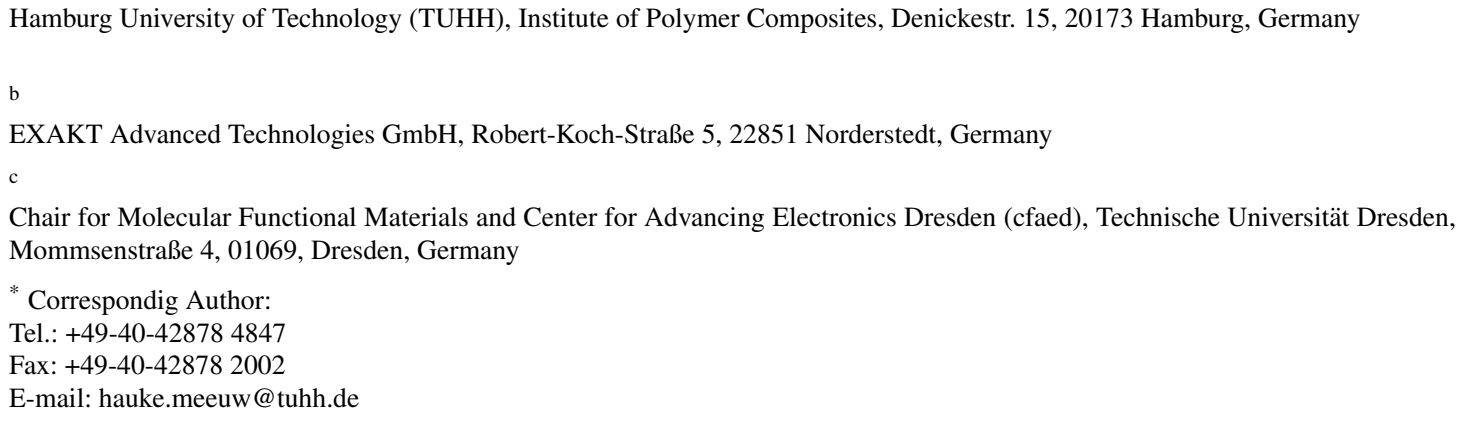


conductivity can be adjusted well with variations of aspect ratio or filler loading and the mechanical properties of the composites are enhanced, too [7-9]. Promising applications for carbon-based nanoparticles are in polymer composites, electrochemical, nanometer-sized electronic devices and printed electronics $[6,10]$. Nowadays, carbon based nanoparticles are becoming available in industrial scale [11] with remaining high compound annual growth rates (CAGR) in the next few years [12], which are predicted to be $18 \%$ and 30-40\% for for the carbon nanotube (CNT) [13] and the graphene market [14, 15], respectively. A demand for standardizised declarations of these materials has been claimed from early on and it still remains actual up to date [16]. The recently $\mathrm{REACH}^{1}$ registration for the ton scale commercialization of carbon nanotubes and graphene [17-19] makes certified particles available for industrial applications. With today's single walled carbon nanotubes (SWCNT) a filler loading of only $0.01 \mathrm{wt} . \%$ results in comparable properties, in terms of electrical conductiviy, to commonly used particles. At the same time, a coloring is enabled [20]. Figure 1.1 shows the value chain to produce carbon nanoparticle enabled materials from the raw material to the final product. The dispersion process is the key limiting factor to overcome [21]. Separation and dispersion of carbon-based nanoparticles is time-consuming and generates high costs in the value chain. Today's approaches for industrial processing are not economic and exhibit a low degree of automation [12]. The lower required filler loading results in a cost saving at the material site. Due to inefficient processes for filler incorporation the production of nano-enabled products generate high costs. Therefore, the cost advantage generated by the low required filler loading gets lost through the value chain. The incorporation of particles is typically realized by dispersion processes like

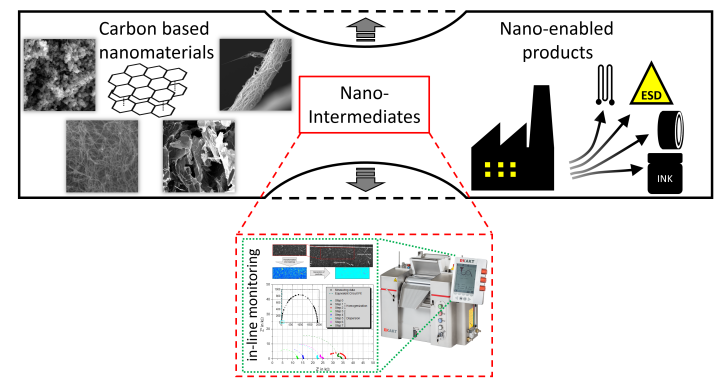

Figure 1.1: Valuechain of carbon nanoparticle products

ultrasonication, high speed stirring or three roll milling (TRM) [22-24]. For water based dispersion the utilization of surfactants as well as ultrasonication lead to efficient results, but are limited to low viscosity systems [25]. For best dispersion results, high shear amplitudes are more effective than an increased shear rate [26]. Therefore, beside the fact that they are scaleable, continous processes are favourable. TRM-technology is capable of incorporating of particles in comparable high-viscous polymer systems, like epoxy resins, and is realizable as a continuous process. Additionally, higher viscous dispersions result in a longer shel life by reduced agglomeration rates [27]. The production of highly concentrated masterbatches with a subsequent dilution to the desired concentration is a cost effective and state of the art approach to process polymer systems containing nanoparticles. By improving the dispersion process this bottleneck vanishes and the cost advantage of carbon nanoparticles can be transferred from the raw material into the final product.

\footnotetext{
1 Registration, Evaluation, Authorisation and Restriction of CHemicals
} 


\section{Theoretical background and state of the art}

A three roll mill consists of three adjacent calendars which rotate in opposite directions with increasing angular velocities and decreasing gap size. Figure 2.1 shows the schematic layout of a three roll mill. The dispersion process can be divided into three parts:
I Material feeding
II Film formation
III Dispersion

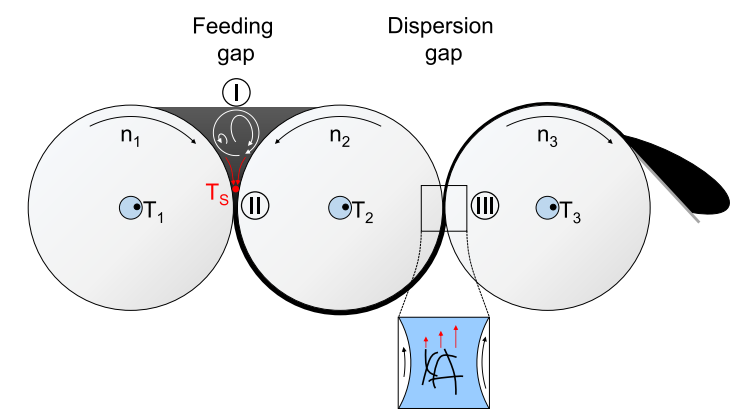

Figure 2.1: Schematic visualization of three roll milling process adapted from [28]

After the dispersion, the apron blade collects the dispersed material, which is subsequently re-fed into the feeding gap, if necessary. The transport of the material through the TRM can be described with a drag and pressure flow [29]. The resulting material flow and line load distribution for $n_{2}>n_{1}$ is shown in figure 2.2. Magnier et al. simulated the calendaring process with two rolls and thermoplastic materials. They showed that the highest loads occur before the gap is smallest [30]. The condition of $n_{2}>n_{1}$ is necessary to guarantee a transfer of the material through the TRM. As shown in figure 2.2, the material sticks on the faster roll. TRM introduces high shear rates into the material. The gradient of the flow velocity $v$ along the gap spacing $h$ gives the shear rate $\dot{\gamma}$.

$$
\dot{\gamma}=\frac{\partial v}{\partial h}
$$

The angular velocity at the surface of the roll is calculated from the roll's diameter $d_{i}$ and its revolution speed $n_{i}$ :

$$
v_{i}=\pi d_{i} n_{i}
$$

The resulting shear rates are highest at the smallest roller spacing $h$, which is also the gap spacing, and can be calculated as follows

$$
\dot{\gamma}=\frac{\pi d\left(\frac{n_{2}-n_{1}}{60}\right) \cdot 10^{-3}}{h \cdot 10^{-6}}
$$

The volume flow can be calculated by following equation.

$$
\dot{V}=\left(V_{1} \cdot h\right)+\frac{1}{2}\left(V_{2}-V_{1}\right) \cdot L
$$

In a previous study, the approaches to monitor and optimize the TRM-process by evaluation of occurring line loads and impedance spectroscopy were introduced [28]. New generation TRM are enabled to measure the occurring line loads between the rolls during dispersion. By evaluation of the absolute complex 
impedance $\left|Z^{*}\right|$ in dependency of the angular frequency $\omega$ detailed information of the resulting electrical conductive particle network structure can be derived. Whereby $\omega$ can be calculated from $\omega=2 \pi f$ with the frequency $f$. Figure 2.3 gives a schematic visualization of the frequency dependent complex impedance resulting from a network of conductive particles in an isolating material. The frequency dependency results from the resistive and capacitive nature of the composites, which are different on macro and micro level. The lower resistance represents the micro scale. The detailed interpretation is given in [28].

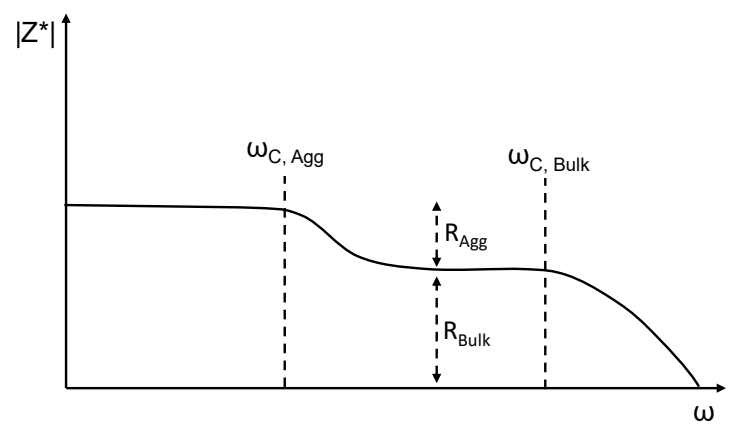

Figure 2.3: Schematic visualization of interpretation of impedance spectroscopy data adapted from [28]

This paper aims on answering following questions:

a) What is the impact of particle type on the line loads during dispersion via TRM?

b) How to interpret the line load data?

c) Are there criteria for an optimum dispersion depending on material properties?

d) What are the mechanisms for dispersion of different particles?

e) What is the impact of matrix viscosity on the dispersion results?

f) Are there differences in dispersion results for lab scale and production TRM? 


\section{Materials and Methods}

To address the previous questions, different carbon particles, namely CB, MWCNT, SWCNT, electrochemically expanded graphite (ExG), functionalized electrochemically expanded graphite (fExG) and few layered graphene, were dispersed in four different epoxy resins. The epoxy resins varied in molecular weight distribution. The dispersion took place on two TRM of different size. The material specifications, used TRM and processing parameters will be introduced in the following subsections.

\subsection{Epoxy resins and carbon nanoparticles}

For dispersion, epoxy resins with different molecular weight distributions were used. This allows to determine the influence of increasing viscosity on the dispersion process at constant processing temperatures. All epoxy resins are based on bisphenol-A-diglycidyl-ether (DGEBA). Epikote 162 offers the lowest viscosity, which increases with Epikote 827, 828LVEL and 828, respectively. The resins were supplied by Hexion, Germany. Table 3.1 lists the properties of the resins according to their data sheets.

Table 3.1: Properties of used epoxy resins

\begin{tabular}{lcccccl}
\hline Resin & Type & $\begin{array}{c}\text { Epoxy } \\
\text { Equivalent } \\
\text { Weight in } \\
\text { g/eq }\end{array}$ & $\begin{array}{c}\text { Epoxy Group } \\
\text { Content in } \\
\text { mmol/kg }\end{array}$ & $\begin{array}{c}\text { Viscosity at } \\
\mathbf{2 5} \text { C in } \\
\text { Pas }\end{array}$ & $\begin{array}{c}\text { Physical } \\
\text { State }\end{array}$ & Remarks \\
\hline EPIKOTE 162 & DGEBA & $170-174$ & $5744-5883$ & $4.0-5.0$ & Liquid & $\begin{array}{l}\text { Distilled, high } \\
\text { purity grade }\end{array}$ \\
\hline EPIKOTE 827 & DGEBA & $179-184$ & $5430-5590$ & $8.0-10.0$ & Liquid & Low viscosity \\
\hline EPIKOTE 828LVEL & DGEBA & $182-187$ & $5340-5500$ & $10.0-12.0$ & Liquid & $\begin{array}{l}\text { Low } \\
\text { hydrolyzable } \\
\text { chlorine, low } \\
\text { viscosity }\end{array}$ \\
\hline EPIKOTE 828 & DGEBA & $184-190$ & $5260-5420$ & $12.0-14.0$ & Liquid & $\begin{array}{l}\text { Standard } \\
\text { unmodified } \\
\text { bisphenol A } \\
\text { resin }\end{array}$ \\
\hline
\end{tabular}

To evaluate the effect of different carbon nanoparticle morphologies on the dispersion process a wide set of different particle types was chosen. Commercial available carbon black Printex L purchased from Orion Engineered Carbons, Luxembourg, offers a spherical shape. It is a carbon black pigment recommended for conductive coating applications. Its structure makes it easy to disperse, because it is not entangled and the size distribution is narrow. MWCNT NC7000, supplied by Nanocyl, Belgium, are cylindrical and rigid tubes. SWCNT Tuball 75, supplied by OCSiAl, Luxembourg, are cylindrical and flexible tubes due to their small diameter. Few layered graphene (FLG) AVAN-2, supplied by AVANZARE Innovación Tecnológica S.L., Spain, offers a planar structure. Aditionally, electrochemically expanded graphite and a functionalized variant were used. The manufacturing was according to the process described by Parvez et al. [31]. TU Dresden produces it under a license from Sixonia Tech GmbH, Germany. The functionalized electrochemically expanded graphite was prepared via in-situ functionalization during electrochemical exfoliation in water. For compounding the functionalized and unfuctionalized ExGs were first separated from the electrolyte and washed with deionized water. Instead of the typically used subsequent sonication, which is employed to destroy the graphene agglomerates and liberate pristine exfoliated sheets, 
the expanded, agglomerated product was transferred into ethanol, to prepare highly concentrated slurries. Specific surface areas were determined by a Surfer Gas Adsorption Porosimeter (Thermo Scientific, USA) using nitrogen. Scanning electron microscopy (SEM) was performed on a Zeiss Supra VP 55 (Zeiss, Germany) with a acceleration voltage between 5 and $10 \mathrm{kV}$ to analyze the morphologies. Additionally, the usage of transmission electron microscopy (TEM) Talos F200X (Thermo Scientific, USA) allowed us to evaluate the number of walls and bundle sizes. An acceleration voltage of $200 \mathrm{kV}$ was used. Carbon particles were ultrasonicated in methanol, placed on a TEM grid and dried at $80^{\circ} \mathrm{C}$. Table 3.2 lists the properties of evaluated particles.

Table 3.2: Properties of used carbon nano particles

\begin{tabular}{|c|c|c|c|c|c|}
\hline Nanoparticle & $\begin{array}{c}\text { BET } \\
\text { surface } \\
\text { area in } \\
\mathrm{m}^{2} / \mathrm{g}\end{array}$ & $\begin{array}{c}\text { Layers, } \\
\text { walls or } \\
\text { bundle } \\
\text { size }\end{array}$ & $\begin{array}{c}\text { Aspect } \\
\text { ratio }\end{array}$ & Shape & $\begin{array}{c}\text { Diameter or } \\
\text { thickness in } \\
\text { nm }\end{array}$ \\
\hline Printex L & 125 & amorphous & 1 & spherical & $31 \pm 8$ \\
\hline NC7000 & 321 & $10 \pm 2$ & 150 & cylindrical & $12 \pm 3$ \\
\hline Tuball 75 & 605 & $11 \pm 3$ & 3570 & cylindrical & $1.4 \pm 0.4$ \\
\hline FLG & 128 & $10 \pm 2$ & 6250 & planar & $4 \pm 1$ \\
\hline $\mathrm{ExG}^{\star}$ & 18 & $47 \pm 11$ & 525 & planar & $19 \pm 5$ \\
\hline $\mathrm{fExG}^{\star}$ & 6 & $52 \pm 19$ & 475 & planar & $21 \pm 9$ \\
\hline
\end{tabular}

* This particle type was delivered solved in ethanol and was dried before measurements.

\subsection{Dispersion and characterization of CNP/EP-composites}

The particles were manually mixed with the epoxy resins. Filler degrees were chosen along the electrical percolation threshold. The given concentrations are calculated for the final composite, including the curing agent. The mixing ratio by weight of the epoxy systems was 100 parts resin and 28 to 30 parts curing agent, depending on the epoxy equivalent weight. The processed masterbatch concentration relates to the pure epoxy system. Dispersion was performed on EXAKT three roll mills 120E-250 and 80E-Plus (EXAKT Advanced Technologies, Germany) with roll diameters of $120 \mathrm{~mm}$ and $80 \mathrm{~mm}$, respectively. The line load measurement was performed for the $120 \mathrm{E}$ with a measuring box, supplied by the TRM manufacturer. The box enables to read out the line force data as well as the product temperature $T_{s}$ (compare figure 2.1). In the TRM 80E-Plus the acquisition of line force data and measurement of the temperatures insinde the three rollers $\left(T_{1}, T_{2}\right.$ and $T_{3}$, see figure 2.1$)$ is directly implemented in the machine. The process parameters for the seven-step dispersion process with decreasing gap spacings on $120 \mathrm{E}$ were adapted from our previous study [28] and are listed in table 3.3. Taking into account equation 2.4, considering the fixed gear ratio of $1 / 3$ between the rollers and the diameter of the rollers, the gap ratio must be as well $1 / 3$.

Figure 3.1 gives the resulting shear rates in dependency of the gap spacings and the chosen roller speeds for diameters of $120 \mathrm{~mm}$ and $80 \mathrm{~mm}$ calculated with equation 2.3. To keep the shear rates compareable on both TRM a roller speed of 450 RPM was chosen for dispersion on the 80E-Plus. The rollers temperature was set to $30^{\circ} \mathrm{C}$ and friction width $L$ was $85 \mathrm{~mm}$ for all dispersion processes on 80E-Plus and $145 \mathrm{~mm}$ on $120 \mathrm{E}-250$ due constraints given by the machine. Table 3.4 gives processing parameters on 80E-Plus. 
Table 3.3: Process parameters for dispersion on three roll mill 120E-250.

\begin{tabular}{cccccc}
\hline Step & $\begin{array}{c}\text { Gap } \\
\text { in } \boldsymbol{\mu m}\end{array}$ & $\begin{array}{c}\text { Gap } \\
\text { in } \boldsymbol{\mu m}\end{array}$ & $\begin{array}{c}\mathbf{n}_{\mathbf{1}} \\
\text { in Rpm }\end{array}$ & $\begin{array}{c}\mathbf{n}_{\mathbf{2}} \\
\text { in Rpm }\end{array}$ & $\begin{array}{c}\mathbf{n}_{\mathbf{3}} \\
\text { in } \mathbf{R p m}\end{array}$ \\
\hline 1 & 120 & 40 & 33 & 100 & 300 \\
\hline 2 & 40 & 13 & 33 & 100 & 300 \\
\hline $3-7$ & 13 & 5 & 33 & 100 & 300 \\
\hline
\end{tabular}

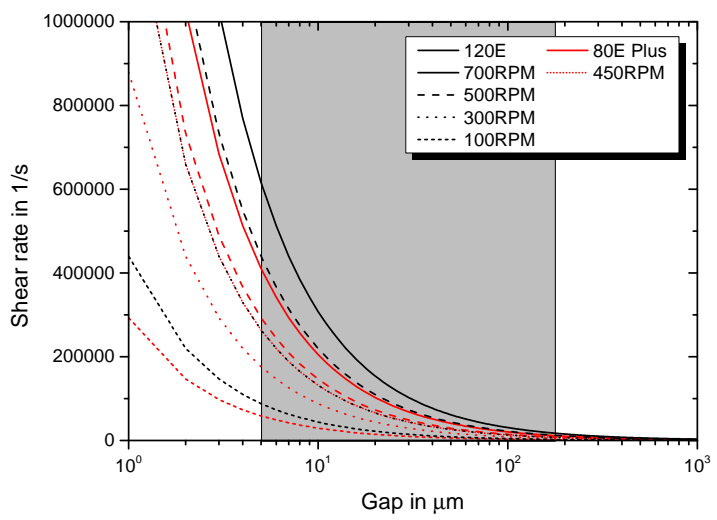

Figure 3.1: Shear rates in TRM in dependency of gap size and revolution speed.

Table 3.4: Process parameters for dispersion on three roll mill 80E-Plus.

\begin{tabular}{cccccc}
\hline Step & $\begin{array}{c}\mathbf{G a p}_{\mathbf{1}} \\
\text { in } \boldsymbol{\mu \mathbf { m }}\end{array}$ & $\begin{array}{c}\mathbf{G a p}_{\mathbf{2}} \\
\text { in } \boldsymbol{\mu m}\end{array}$ & $\begin{array}{c}\mathbf{n}_{\mathbf{1}} \\
\text { in } \mathbf{R p m}\end{array}$ & $\begin{array}{c}\mathbf{n}_{\mathbf{2}} \\
\text { in } \mathbf{R p m}\end{array}$ & $\begin{array}{c}\mathbf{n}_{\mathbf{3}} \\
\text { in } \mathbf{R p m}\end{array}$ \\
\hline 1 & 120 & 40 & 50 & 150 & 450 \\
\hline 2 & 40 & 13 & 50 & 150 & 450 \\
\hline $3-7$ & 13 & 5 & 50 & 150 & 450 \\
\hline
\end{tabular}

After each dispersion step an impedance spectroscopy and a rheological characterization was performed. The procedure for the impedance spectroscopy was adapted from [28]. The used impedance spectrometer was a 4284A precision LCR meter, HP, USA, linked with a GBIB interface to Labview. A small amount of epoxy/nano particle composite was placed in a PMMA cylinder. The inner diameter was $12 \mathrm{~mm}$. Two cylindrical aluminum electrodes were pushed from both sides into the cylinder. The excess material could leak from the cylinder through a small hole. The final spacing was $10 \mathrm{~mm}$. Measuring voltage was 1 V. For rheological characterization a ARES RDA-III 28, TA Instruments, USA, rheometer was used. Strain-sweeps were performed from $0.1 \%$ to $100 \%$ shear strain at a test frequency of $5 \mathrm{~Hz}$ to determine the complex viscosity. Test setup was a plate-plate configuration with a radius $R$ of $40 \mathrm{~mm}$ and a spacing $h$ of $500 \mu \mathrm{m}$. The chosen gap prevents big agglomerates being trapped between both plates. Infrared thermography images during dispersion were taken with a A640, FLIR, USA. 


\section{Results and discussion}

\subsection{Influence of processing machine}

For determination of influences resulting from the size of the processing machine $0.3 \mathrm{wt} \%$ MWCNT NC7000 were dispersed on both TRM. The line force as well as the temperatures were monitored. Figure 4.1 gives the results from the dispersion processes. Monitored data from the 120E-250 (figure $4.1 \mathrm{a}$ )) show a constant value of the line loads in the first homogenization step. Both occurring line loads are at comparable level. In the second homogenization step at smaller gap spacing, the line force signal exhibits a line force increase of both signals at its end. This contributes to a separation of the material, which is clearly visible at the apron blade. The material is drier at the end of this step. All following dispersion steps result in the same curves, which are at a constant level. For the 120E-250 equipped with the measuring box the signal to noise ratio is very high. In every step, the temperature drops towards $30^{\circ} \mathrm{C}$ at the beginning and rises during the dispersion step. Figure $4.1 \mathrm{~b}$ ) shows the results gained by dispersing the same material on the 80E-Plus. In the first homogenization step the line force drops for both gaps during processing. At the end of this step the line force rises. In the second step the line loads decrease in the beginning and then increase due to separation. This material separation has a high impact on the line force of gap 2. For the next two steps the line force drops during the whole dispersion time. At the end of this step the line force slightly increases. The last three steps show a continuous decrease of the line force with processing time. In general, the line force starts at a higher value compared to the last value of the previous step and decreases. Temperatures inside the rollers do not increase. A comparison of processing times by taking into account the variation of friction width $L$ leads to a $20 \%$ increase of production capacity by using the $120 \mathrm{E}-250$ model. All further dispersions were processed on the $80 \mathrm{E}-$ Plus. Gathered impedance spectroscopy results of the dispersions, displayed in figure 4.2, show that the
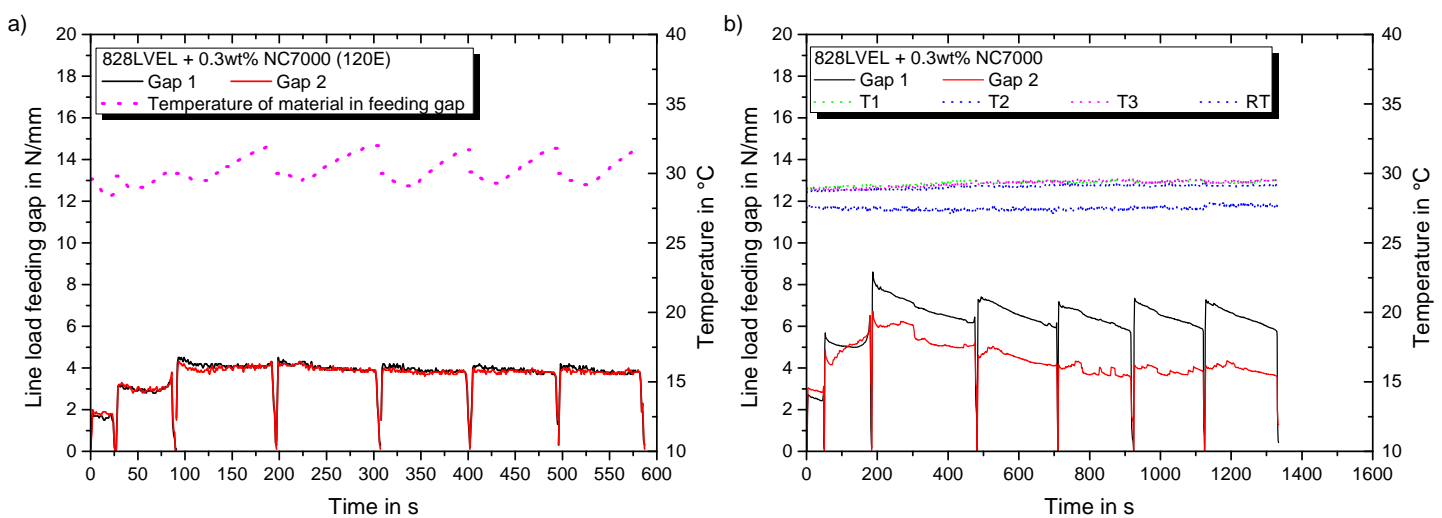

Figure 4.1: Line force data for dispersion process on a) 120E-250 and b) 80E-Plus.

dispersion quality is TRM independent. Resulting impedance spectra of two dispersion processes on 80EPlus verify the high repeatability of the process.

For improved understanding and correct interpretation of the resulting TRM-data, the influence of matrix viscosity, filler content and type are evaluated. 


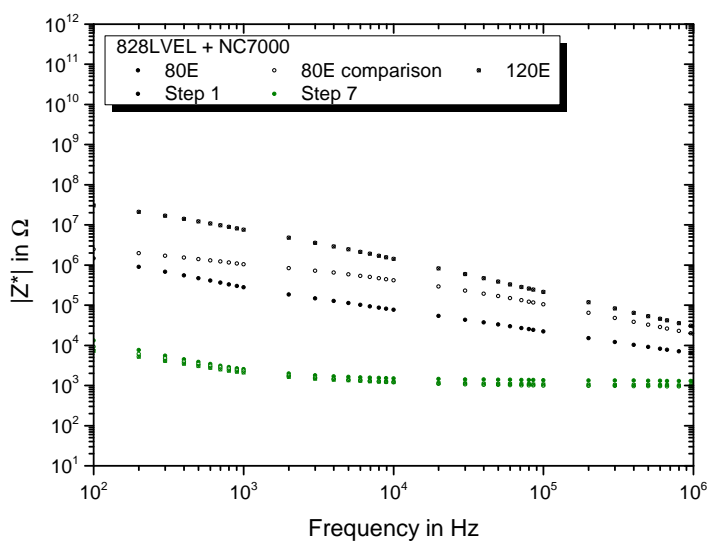

Figure 4.2: Absolute impedance $\left|Z^{*}\right|$ for $0.3 \mathrm{wt} . \%$ NC7000 dispersed in Epikote 828LVEL on 120E-250 and 80E-Plus.

\subsection{Influence of resin viscosity}

For evaluation of the impact of matrix viscosity on the dispersion process $0.5 \mathrm{wt} \%$ NC7000 were dispersed in Epikote 162, 827 and 828. Figure 4.3 a) gives the line force development of the dispersion processes with intermediate impedance spectroscopy measurements.
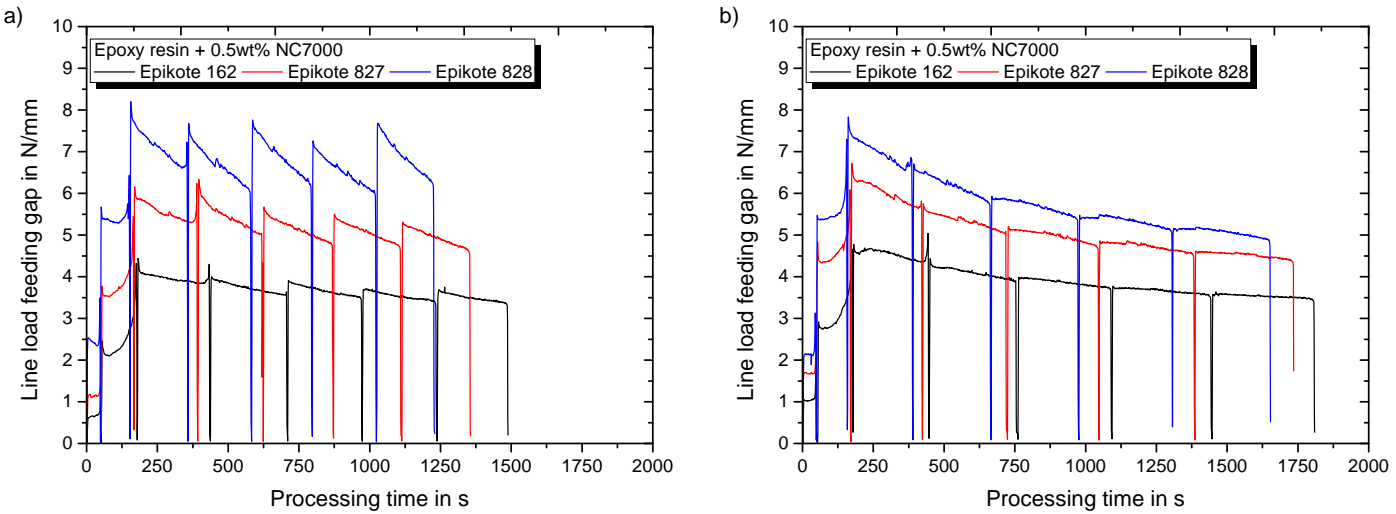

Figure 4.3: Influence of resin viscosity on line force for dispersion of $0.5 \mathrm{wt} \%$ in epoxy resins with different molecular weight distributions. a) dispersion with a break of 15 minutes for impedance spectroscopy measurements after each step; b) continous dispersion process.

All curves show similar curve characteristics. In the first step the line load is constant over the processing time and at the end it raises drastically due to separation. In the second step the line load drops in the beginning and afterwards raises with increasing slope until the end of this step. Until the third step the initial line load rises. This originates from decreasing gap spacing, which results in higher compression of the material dragged into the gap. The third step shows a decrease of the line load during dispersion. In the end it rises again. All following steps exhibit a continuous decrease of line load and possess the same initial line load value. With increasing resin molecular weights, the line loads rise. Additionally, the processing time decreases by $15 \%$. This results from the higher cohesive nature of the higher molecular weight resin. Comparing these results to a continuous dispersion process, where the material is directly 
re-feed into the feeding gap after each step without additional time consuming characterizations, the curve characteristics change. Figure $4.3 \mathrm{~b}$ ) shows the line load curves for a continuous process. The first two steps are similar to the non-continuous process. Beginning with the third cycle the line load constantly decreases. An increase at the end of the step is only observable for the third step. The initial line load is similar to the last value of the previous step. The decrease over processing time seems to be a temperature related effect. This will be addressed in the next section. Figure 4.4 gives the impedance spectroscopy curves after step 1, 3, 5 and 7 . In the low frequency range, which can be considered as bulk behavior, $\left|Z^{*}\right|$ shows nearly the same value for all configurations after step 3 and remains nearly constant. On macro scale the material behavior does not change anymore. This correlates with the extinction of material separation after dispersion step 3 in the line load curves. In the high frequency range $\left|Z^{*}\right|$ increases with further dispersion. Here, the material with Epikote 828 results in highest complex impedance after final dispersion step. With decreasing molecular weight of the resin, the complex impedance decreases as well. This indicates an improved dispersion on micro scale due to the higher molecular weight, inducing improved shear stress transfer to separate the agglomerates. This result is supported by the rheological results, given in figure 4.5. As expected, the complex viscosity is lowest after dispersion step 1 for the low molecular weight resin Epikote 162 and increases with molecular weight increase. After the final dispersion step, the high molecular weight Epikote 828 offers lowest viscosity. Low complex viscosity results from less particle interaction within the material. Correlating this with the previous impedance spectra confirms the conclusion that the particles are better dispersed. 


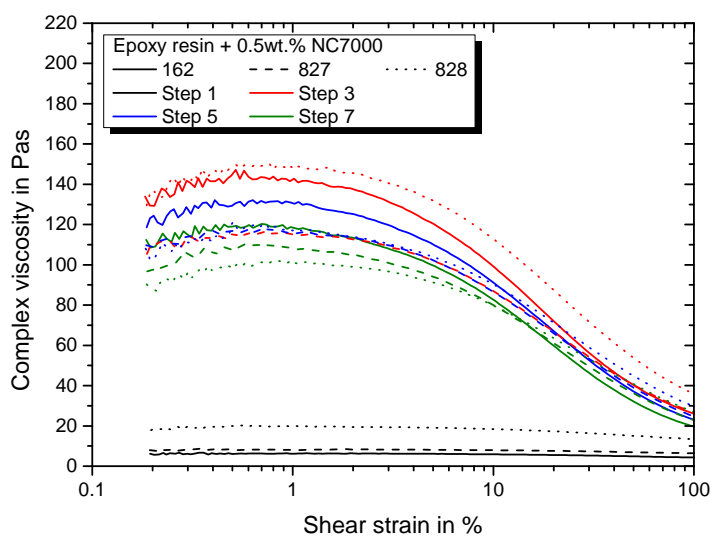

Figure 4.5: Complex viscosity resulting from strain-sweeps in dependency of resin viscosity for NC7000 dispersions.

\subsection{Temperature dependency of dispersion process}

A dispersion of a masterbatch consisting of $1 \mathrm{wt} . \%$ NC7000 in Epikote 828LVEL was monitored by infrared thermography to analyze the temperature development over the dispersion process and its effect on the line load. Figure 4.6 a) shows the line load development and temperature development over the processing time. Temperature inside the rollers increases sligtly. The characteristics of the curve are similar to the already shown results. After step 3 no more separation occurs. To monitor the occurrence of material separation a line load increase at the end of the dispersion step must be identified. This is visualized by the first process time derivative of the line load. If the derivative curve is negative, no separation occurs. A positive derivative indicates a separation peak, which gives an adequate criterion to evaluate the dispersion quality. Figure $4.6 \mathrm{~b}$ ) gives the process time derivative of the line load in the feeding gap. After step 3 the criteria is fulfilled. The temperature development of the material is given for both gaps in figure 4.9 a). For correlation with line load data several areas of interests were chosen, which are given
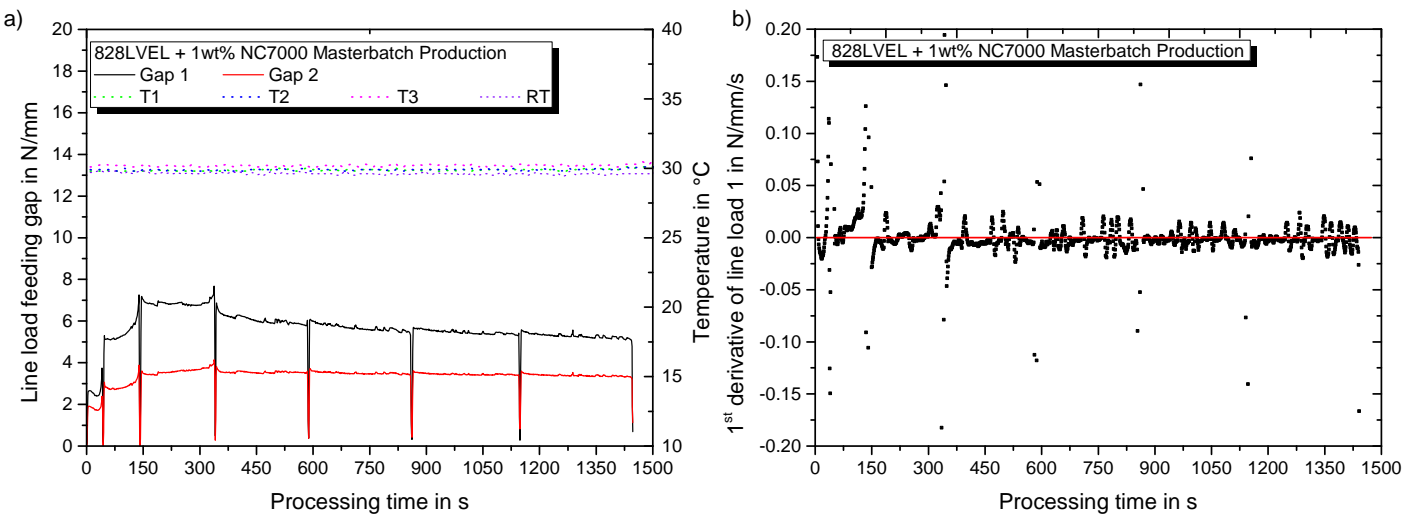

Figure 4.6: Dispersion process of 1 wt.\% NC7000 in Epikote 828LVEL: a) line load and temperature development within the rollers, b) first derivative of line load in the feeding gap.

in figure 4.7. The temperature was monitored in the feeding gap (1), dispersion gap (2), material on the apron blade (3) and for the apron blade itself $(4,5)$. 
1

2

3

4

5

6

7

8

9

10

11

12

13

14

15

16

17

18

19

20

21

22

23

24

25

26

27

28

29

30

31

32

33

34

35

36

37

38

39

40

41

42

43

44

45

46

47

48

49

50

51

52

53

54

55

56

57

58

59

60

61

62

63

64

65

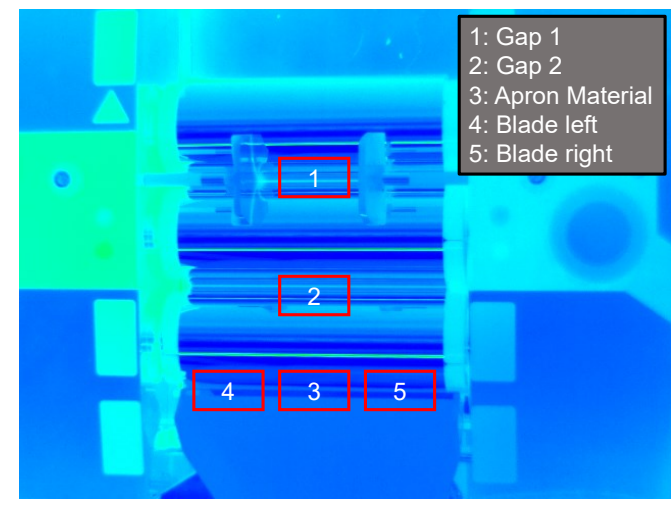

Figure 4.7: Areas of interest fo the 1 wt.\% NC7000 masterbatch dispersion 

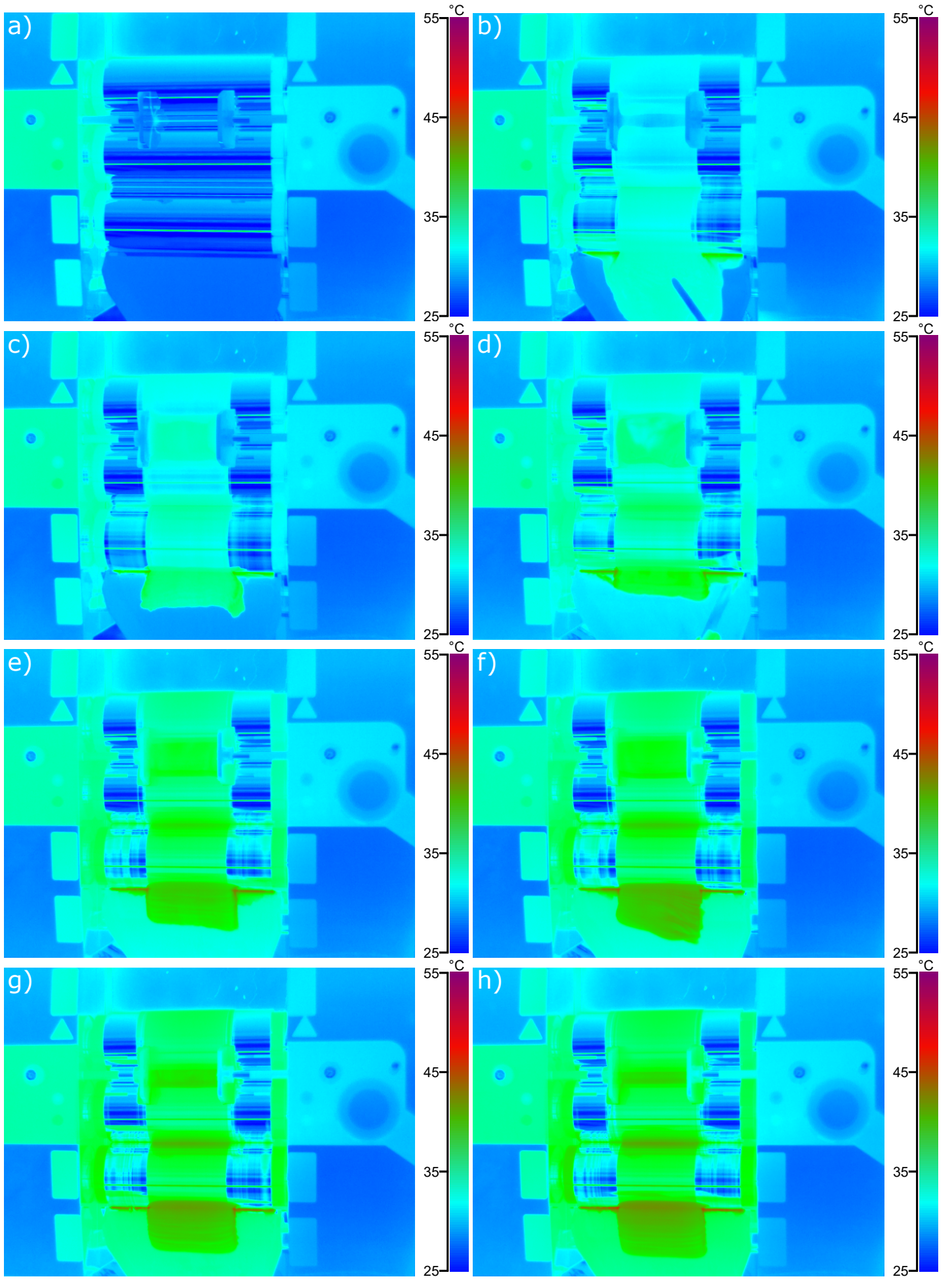

Figure 4.8: Temperature development during dispersion visualized by infrared thermography for a) initial state, b) after step 1, c) after step 2, d) after step 3, e) after step 4, f) after step 5, g) after step 6, h) after step 7. 
Figure 4.8 a) gives the temperature distribution at the initial state of the machine. The rollers are on the set temperature of $30^{\circ} \mathrm{C}$ and in steady state. After the first dispersion step (figure $4.8 \mathrm{~b}$ )) a temperature increase of the material becomes visible. At the parts of the apron blade, where the metal blade runs without material, the temperature increase is most pronounced. For the remaining steps (figure $4.8 \mathrm{c}$ ) to h)) the heat generation is more and more pronounced. Finally, a temperature increase over $10^{\circ} \mathrm{C}$ can be observed for the dispersed material. Curve characteristics of temperature development in the dispersion gap correlate with the line load curve. The temperature and the line load approach a threshold. A temperature increase results in lower viscosities of the matrix material, which lowers the occurring line loads. Figure 4.9 b) verifies that the highest heat input results from the steel apron blade which runs on the steel roller without a resin film acting as lubricant in between.
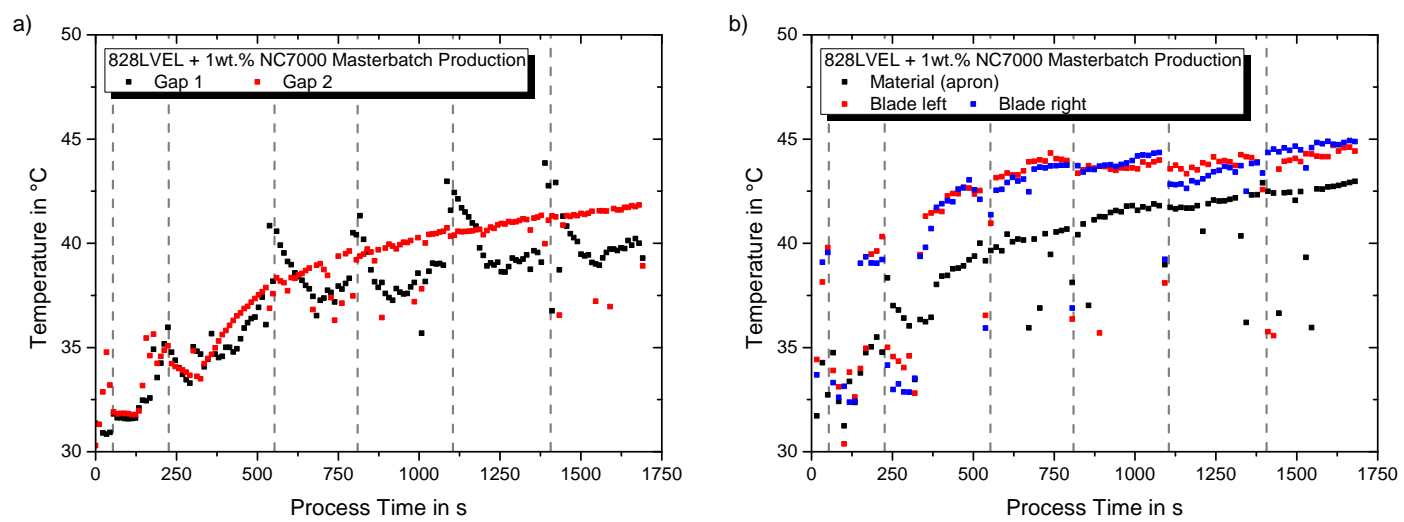

Figure 4.9: Temperature development of dispersion process with $1 \mathrm{wt}$ \% NC7000 in Epikote 828LVEL: a) material in feeding and dispersion gap, b) material at apron blade and the blade itself.

\subsection{Carbon Black}

For evaluation of the influence of spherical particles on dispersion behavior as well as the influence of filler-content, carbon black Printex L was dispersed in Epikote 828LVEL with concentrations of 1, 4, 8 and $12 \mathrm{wt} . \%$. Figure 4.10 shows the resulting line load and temperature development with process time. The line load curves decrease within each step. The initial value increases again for the first three steps and remains constant in the following steps. No increase in temperature can be observed inside the rollers. Figure $4.10 \mathrm{~b}$ ) gives the first derivative of the line load of the feeding gap. In none of the dispersion steps separation occurs, judging from the fact that the values are always negative at the end of each dispersion step. Increasing filler contents result in higher line loads and an increase in processing time (figure 4.11 a)). This contributes to the pronounced filler network for highly filled polymers, changing the viscoelastic behavior of the material more to a solid-like nature. Displayed impedance spectra in figure 4.11 b) reveal different dispersion mechanisms with varying filler content. For $1 \mathrm{wt} \%$ at low frequencies a conductive network exists after the first dispersion step. By further dispersion, the capacitive nature of the material becomes more dominant. After seven dispersion steps the composite offers a pure insulating nature. For $2 \mathrm{wt} . \%$ the complex impedance decreases with further dispersion and reaches a steady value after step 3. This behavior is also observed for 8 and $12 \mathrm{wt} . \%$ filler loading. After step 3 the impedance does not change significantly by further processing. Figure 4.12 visualizes the governing mechanism for this material behavior. The particles are present in their agglomerated state. Mixing them into the resin 

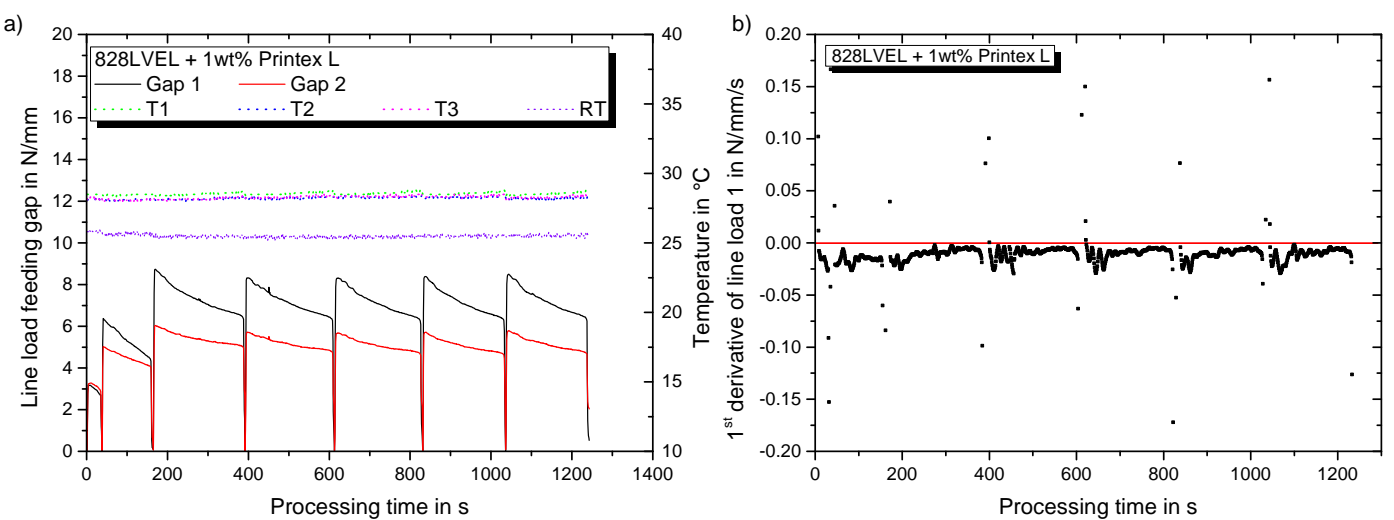

Figure 4.10: Carbon black Printex L dispersed in 828LVEL: a) line load and temperature development for $1 \mathrm{wt}$. $\%$, b) first derivative of line load in the feeding gap.
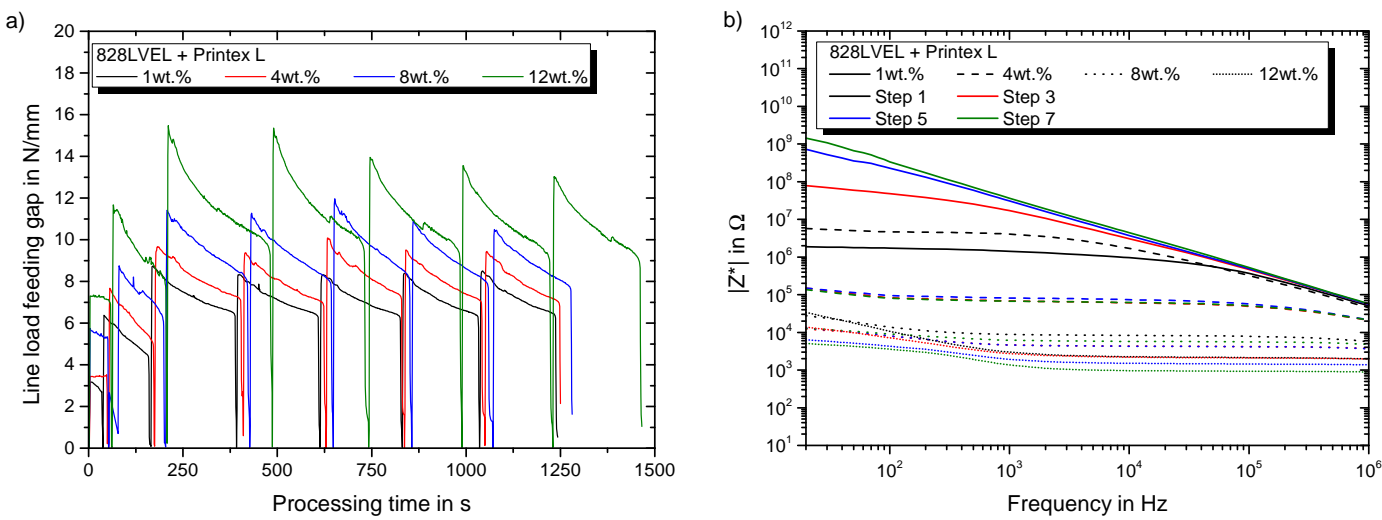

Figure 4.11: Carbon black Printex L dispersed in 828LVEL: a) influence of filler content on the line load, b) comparison of impedance spectra for $1,4,8$ and $12 \mathrm{wt} . \%$

and homogenization during the first dispersion step leads to a conductive network (red line in figure 4.12 a)). The size of the spherical agglomerates is of such a size that they touch each other. By further dispersion, the size of the agglomerates is reduced and they finally fill the polymer without touching each other (compare figure 4.12 b) and c)). Increasing the filler content changes the mechanism. This is visualized by figure $4.12 \mathrm{~d}$ ) to f). After the first homogenization step, the agglomerates touch each other and by further dispersion steps a higher redundancy of the particle network builds up by forming more conductive paths. This improves the final conductivity. 
a)

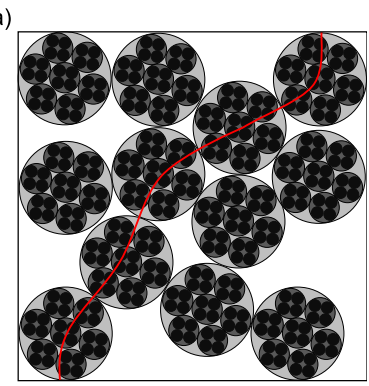

d)

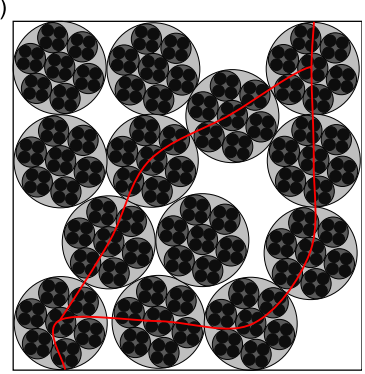

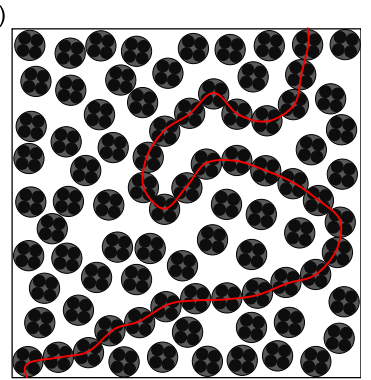

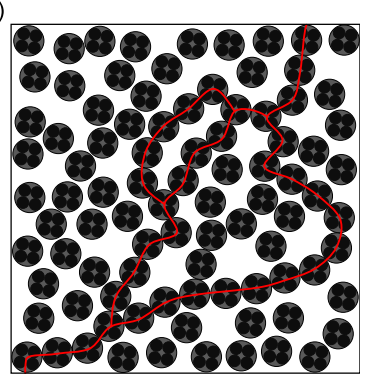

c)
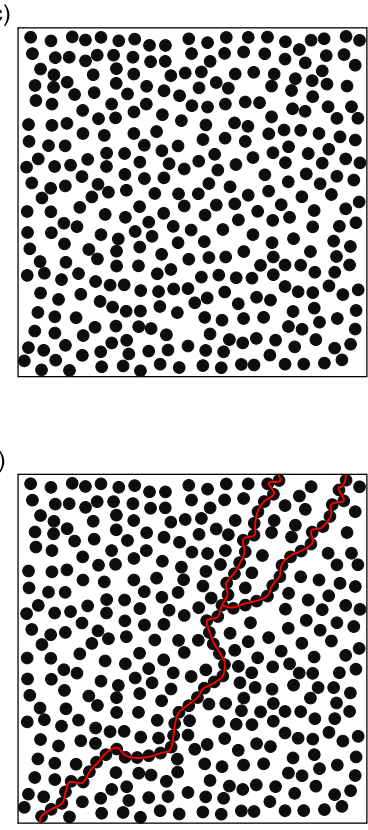

Figure 4.12: Schematical visualization of the separation mechanism and agglomerate size change over through the dispersion process and its effect on conductive paths in the material: a) to c) low filler content, d) to f) high filler content

\subsection{Multi walled carbon nanotubes}

The impact of rigid cylindrical particles on the process data is analyzed by dispersing $0.1,0.3,0.5$ and 0.7 wt.\% of NC7000 MWCNT in Epikote 828LVEL. The results of the $0.3 \mathrm{wt} \%$ were already discussed in section 4.1. Figure 4.13 a) and b) show no significant differences between line load and processing time with increasing filler content. Just the line load in gap 2 slightly decreases. Impedance spectroscopy data
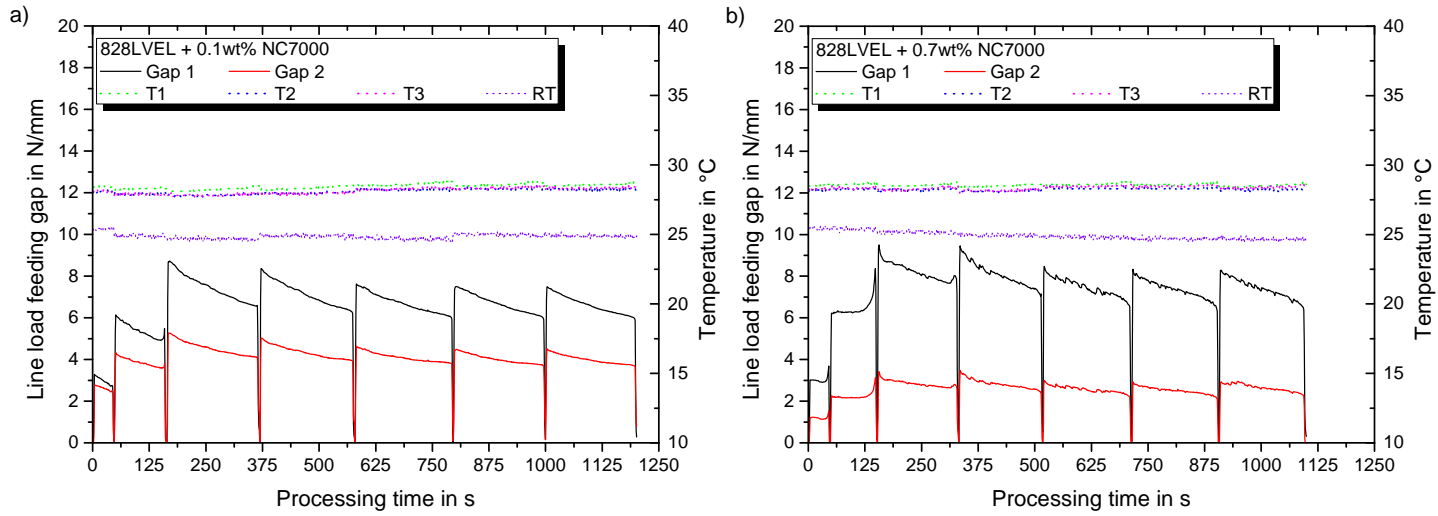

Figure 4.13: MWCNT NC7000 dispersed in 828LVEL: a) line load and temperature development for $0.1 \mathrm{wt} . \%$, b) line load and temperature development for $0.7 \mathrm{wt} \%$. 
reveal a change in mechanisms for this material, too (compare figure 4.14) . For $0.1 \mathrm{wt} . \%$ the impedance drops for low frequencies from first to third dispersion step and increases again with further dispersion. Beginning with $0.3 \mathrm{wt} . \%$ the material shows the same behavior as carbon black. After the third dispersion step the no further decrease in impedance is achieved. This correlates with the extinction of the separation peak. Summarizing, rigid particles like CB or MWCNT need only few dispersion steps to be

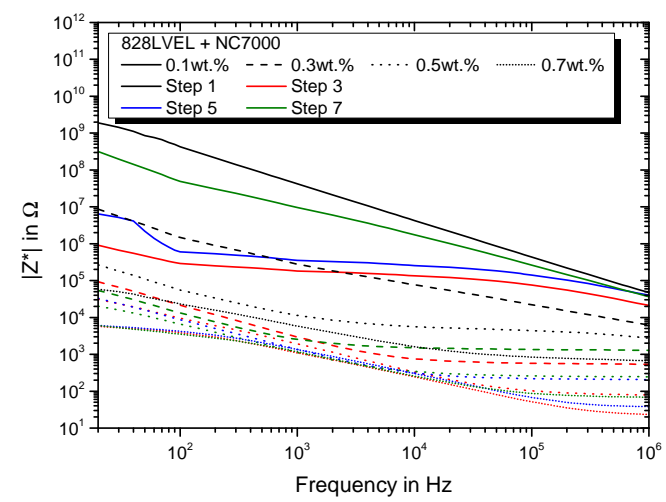

Figure 4.14: Comparison of impedance spectra for $0.1,0.3,0.5$ and $0.7 \mathrm{wt} . \%$ NC7000 in $828 \mathrm{LVEL}$

homogeneously dispersed. Higher filler content increases processing time for $\mathrm{CB}$ but shows no significant increase for MWCNT.

\subsection{Single walled carbon nanotubes}

The impact of flexible cylindrical particles is analyzed by dispersing $0.01,0.05,0.1$ and $0.5 \mathrm{wt} . \%$ of Tuball SWCNT in Epikote 828LVEL. For $0.01 \mathrm{wt} . \%$ filler concentration the separation peak vanishes after step 6, compare figure 4.15 a). For 0.05 wt.\% the separation peak is more pronounced and does
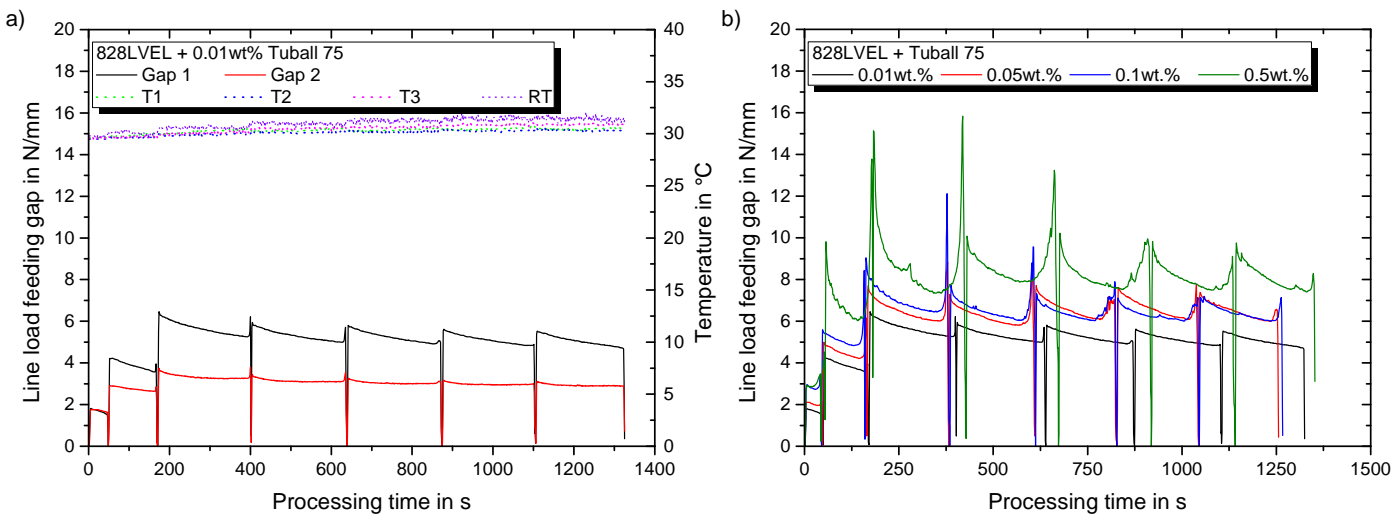

Figure 4.15: Tuball 75 dispersed in 828LVEL: a) line load and temperature development for $0.01 \mathrm{wt}$ \% b) comparison of line loads for $0.01,0.05,0.1$ and 0.5 wt. $\%$

not vanish (compare figure $4.15 \mathrm{~b}$ )). It remains even after seven dispersion steps. A further increase 
of filler loading by one order of magnitude to $0.5 \mathrm{wt} . \%$ results in even more pronounced separation in the first dispersion steps. The line loads of the last dispersion steps look similar to in the last steps for filler contents above $0.05 \mathrm{wt} . \%$. A filler content increase does not affect the processing time, although it leads to an increase in line load. Figure 4.16 gives an overview of the resulting impedance spectra. For all filler loadings, the complex impedance at low frequencies decreases by further dispersion. For filler contents above $0.05 \mathrm{wt} . \%$ the low frequency complex impedance does not change significantly for more than three dispersion steps. Only at comparable high filler loading of $0.5 \mathrm{wt} . \%$ a change of the micro network can be observed at high frequencies. The difference of this particle type to the others lays in

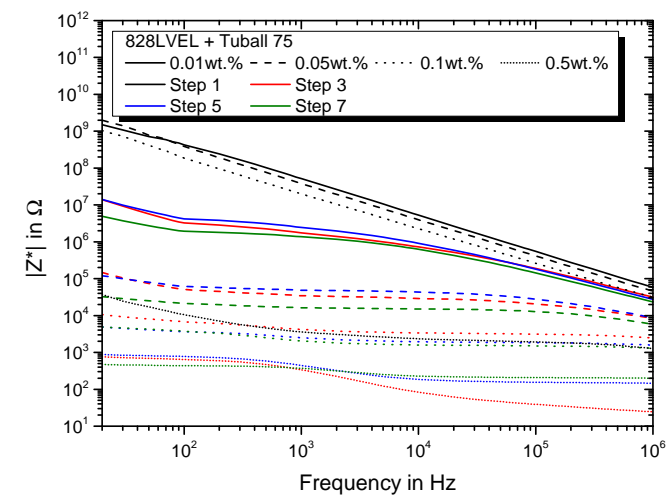

Figure 4.16: Comparison of impedance spectra for $0.01,0.05,0.1$ and $0.5 \mathrm{wt} \%$ Tuball 75 in $828 \mathrm{LVEL}$

their microstructure. SEM image shown in figure 4.17 reveals a highly entangled and bundled structure of the flexible SWCNT. This explains the high tendency for separation of matrix and filler, because the material is hard to homogenize. This benefits the build-up of an electrical conductive network and explains their low percolation threshold. This phenomenon is also observed by Yoon et al. [24] and Leopold et al. [32]. An optimization of the dispersion process for this particle type is only possible by utilizing

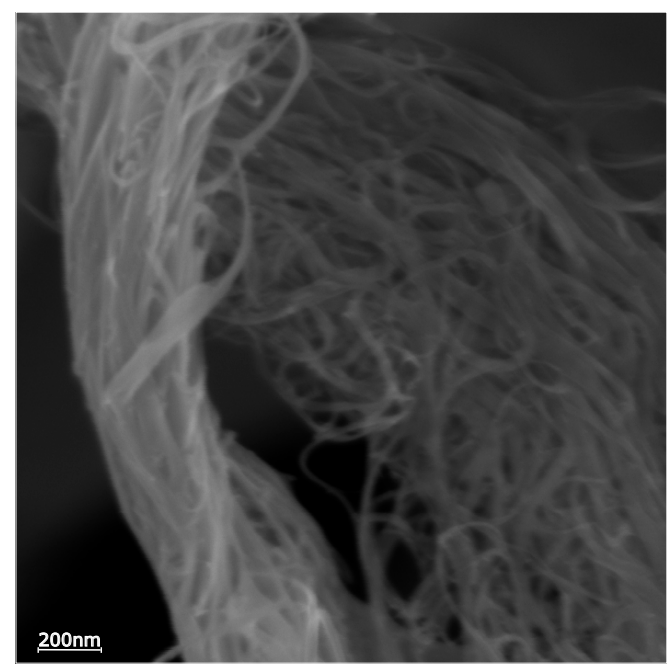

Figure 4.17: Scanning electron microscopy of Tuball 75 SWCNT 
additional impedance spectroscopy measurements. With regard to electrical properties, no significant change is given after maximum five dispersion steps.

\subsection{Commercial Few Layered Graphene}

The impact of planar particles on the process is analyzed by dispersing $0.5,1$ and $2 \mathrm{wt} . \%$ of FLG in Epikote 828LVEL. A filler content beyond $2 \mathrm{wt} . \%$ could not be processed, because the mixture became too dry. Figure 4.18 a) shows the line load data for the lowest concentration of FLG. After the seventh step of the dispersion process the separation peak still exists. This is also revealed by the first derivative of the line load, compare figure 4.18 b). Figure 4.19 a) compares the line load data for increasing filler
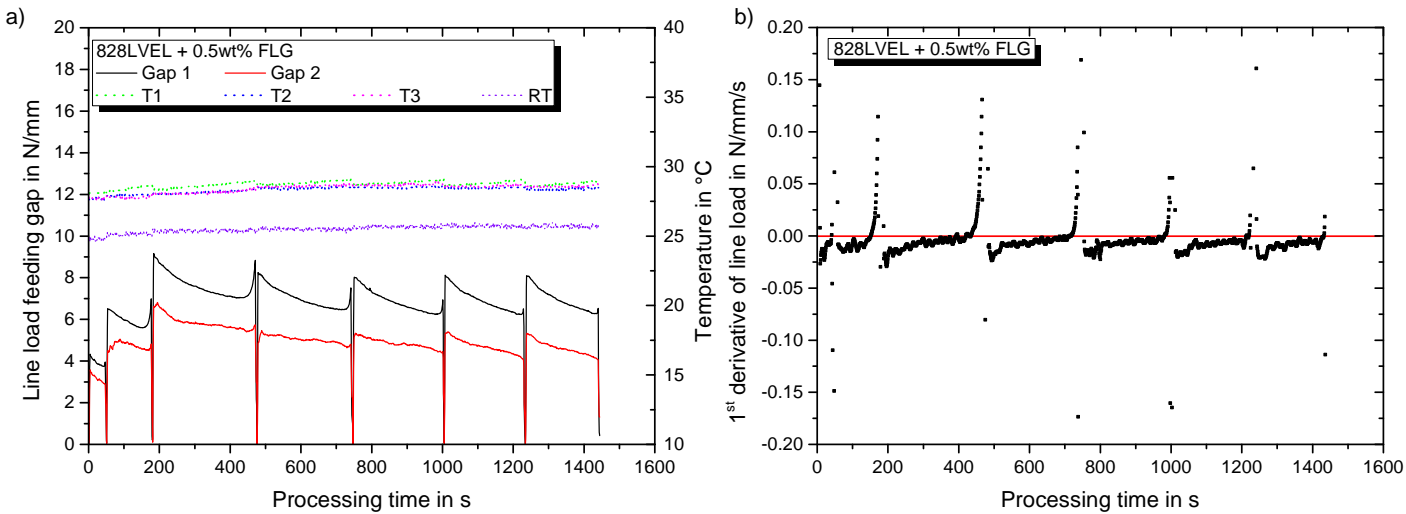

Figure 4.18: Few Layered Graphene dispersed in 828LVEL: a) line load and temperature development for 0.5 wt. $\%$, b) first derivative of line load in the feeding gap.

loadings. The separation peak vanishes for $2 \mathrm{wt} . \%$ after dispersion step 7 . With increasing filler content the processing time shortens. The impedance spectra given in figure $4.19 \mathrm{~b}$ ) reveal a completely different
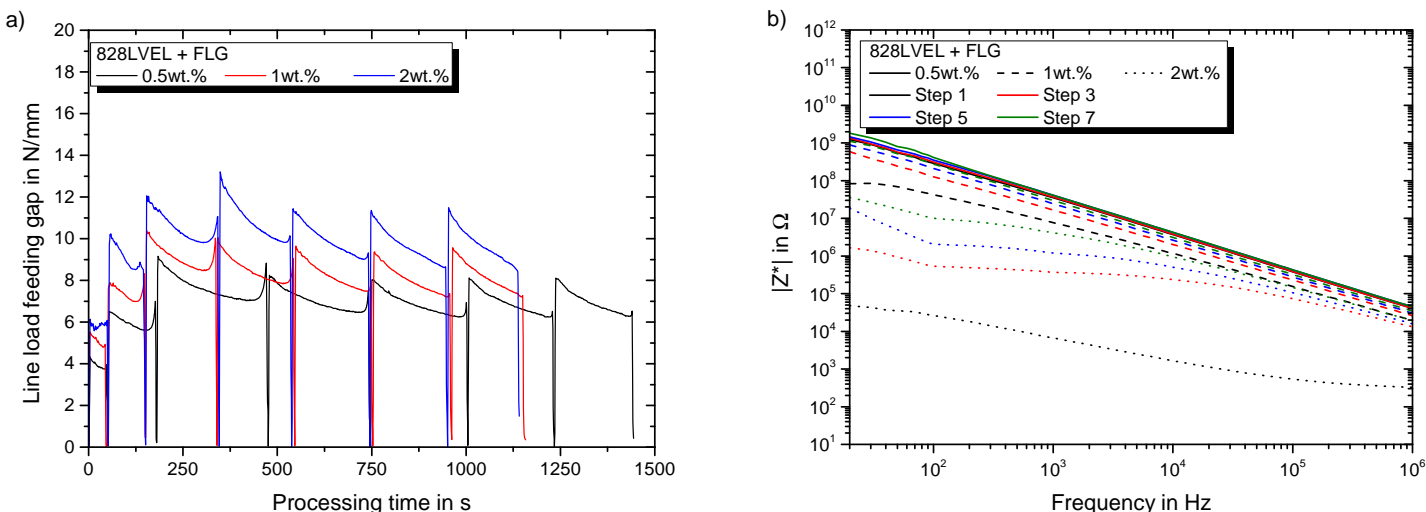

Figure 4.19: Few Layered Graphene dispersed in 828LVEL: a) line load for 0.5, 1 and 2 wt.\%, b) impedance spectra for different filler contents and dispersion steps.

mechanism for this particle type. For all filler concentrations, the capacitive contribution becomes more 
pronounced by further dispersion. A filler content of $0.5 \mathrm{wt} . \%$ does not lead to a conductive network at any point. Increasing the filler content to $1 \mathrm{wt} . \%$ the composite starts to exhibit a low conductive network, which becomes purely capacitve after dispersion. A plateau in the low frequency as well as high frequency region exists for $2 \mathrm{wt} . \%$ of FLG in epoxy in the initial state. As already mentioned, the lower plateau stands for a conductive micro network and vanishes by dispersion. The low frequency plateau shifts to much higher values over the processing time. This observation leads to the conclusion that a mechanical exfoliation of the graphene sheets takes place. Mechanical exfoliation of graphene via TRM is well described in publications of Li et al. [33,34]. Even laminar flows within the TRM are sufficient to achieve exfoliation [35].

\subsection{Electrochemically Expanded Graphite}

The influence of electrochemically expanded graphite stabilized in ethanol in comparison to FLG is analyzed by dispersion of 1,2 and 3 wt.\% of it in Epikote 828LVEL. First of all, it has to be stated that high filler contents as $3 \mathrm{wt}$.\% were dispersible without complications due to the pre-wetting with ethanol. The ethanol lowers the viscosity of the composite significantly. Figure 4.20 a) shows the line load data over process time for $1 \mathrm{wt} . \%$ filler content. The material was processed until no more separation occurred, compare figure $4.20 \mathrm{~b}$ ). This took 10 dispersion steps. Additional steps were performed at a gap spacings of $13 \mu \mathrm{m}$ and $5 \mu \mathrm{m}$, respectively. The line load raises from nearly $0 \mathrm{~N} / \mathrm{mm}$ to $8 \mathrm{~N} / \mathrm{mm}$ from step to step. This is due to the evaporation of the ethanol on the enormous surface of the tempered rollers and improved dispersion.
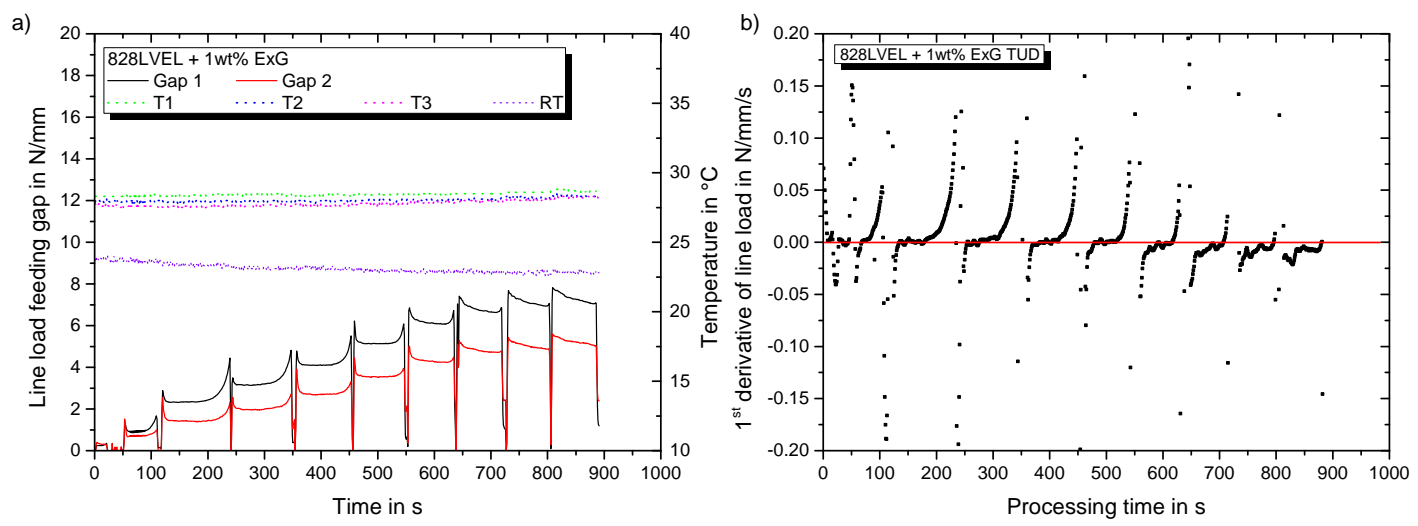

Figure 4.20: Exfoliated Graphene dispersed in 828LVEL: a) line load and temperature development for 1 wt.\%, b) first derivative of line load in the feeding gap.

The influence of filler content on line load is shown in figure 4.21 a). An increase of filler content accompanies with longer processing times. This is visible in the first two dispersion steps. For the $1 \mathrm{wt} . \%$ a lot of separation peaks occurred during processing. This attributes to non-continuous material feeding. Figure $4.21 \mathrm{~b}$ ) gives the impedance spectra for the dispersed filler contents. The composite with $1 \mathrm{wt} . \%$ starts with a low conductive filler network, which vanishes over the dispersion process. This correlates with the results from FLG, allowing the conclusion that mechanical exfoliation leads to this behavior. For 2 and $3 \mathrm{wt} . \%$ the impedance in the low frequency regime decreases from step 1 to step 2 . This results from the volume loss due to evaporating ethanol. After step 3 the low frequency impedance increases, but the plateau does not vanish. A low conductive network still exists. Dispersion processes of the same 

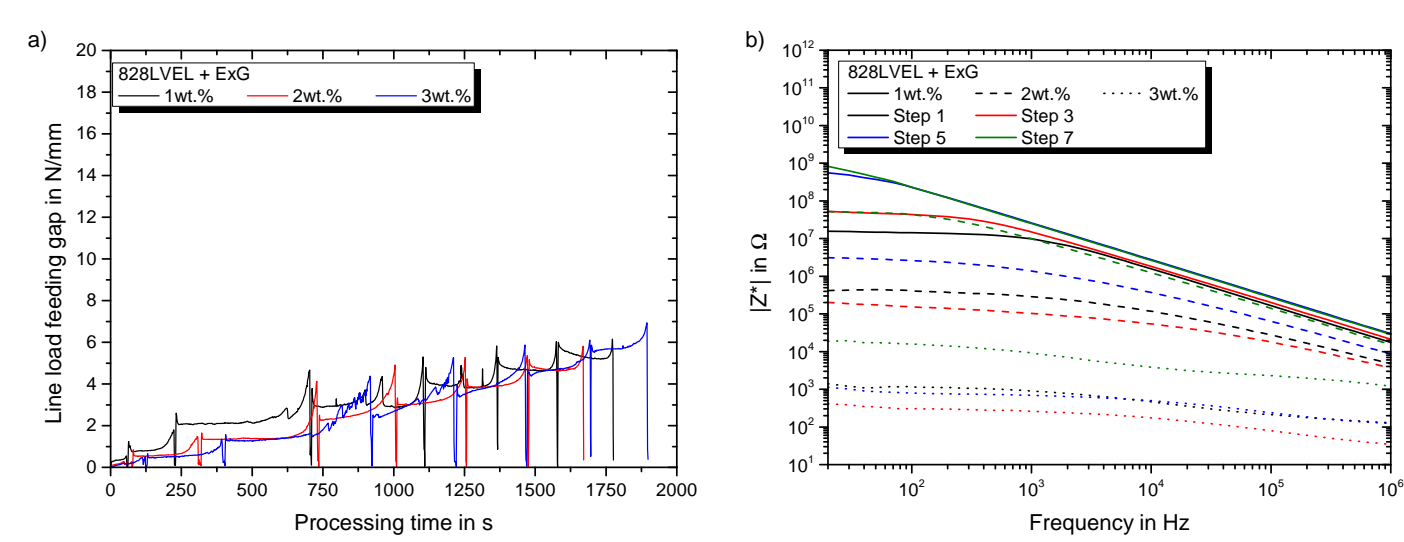

Figure 4.21: Exfoliated Graphene dispersed in 828LVEL: a) line load for 1, 2 and 3 wt.\%, b) impedance spectra for different filler contents and dispersion steps.

material configuration results in the same filler network structure for this material, too. Impedance spectra for $1 \mathrm{wt} . \%$ processes, shown in figure 4.22 , demonstrate the reproducibility of the process.

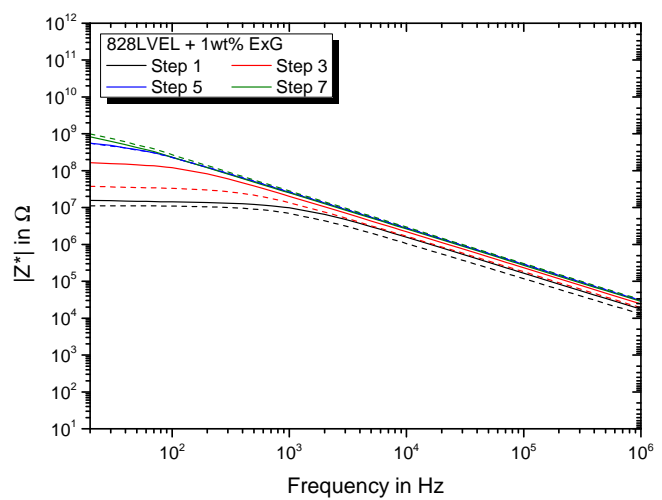

Figure 4.22: Comparison of two dispersion processes with $1 \mathrm{wt} \%$ EG in Epikote 828LVEL

\subsection{Functionalized Electrochemically Expanded Graphite}

The impact of functionalization of electrochemically expanded graphite stabilized in ethanol in comparison to conventional ExG is analyzed by dispersion 1,2 and 3wt.\% of it in Epikote 828LVEL. The dispersion curves show the same characteristics as the dispersion of ExG. Ethanol evaporates and increases the viscosity. For this material only 9 dispersion steps are necessary for best homogenization. Figure 4.23 a) gives the line load data for a 11 step dispersion process of $1 \mathrm{wt} . \%$. The corresponding derivative of the line load is shown in figure $4.23 \mathrm{~b}$ ). Impedance spectra, displayed in Figure 4.24, show a continuous increase of low frequency impedance for all filler concentrations. For $1 \mathrm{wt} . \%$ the conductive network vanishes. It remains for higher filler concentrations after dispersion. This material results in higher capacitive nature compared to ExG. This indicates improved dispersion and wetting behavior. Summarizing, all investigated planar particles (FLG, ExG and fExG) show predominating mechanical exfoliation. 
a)

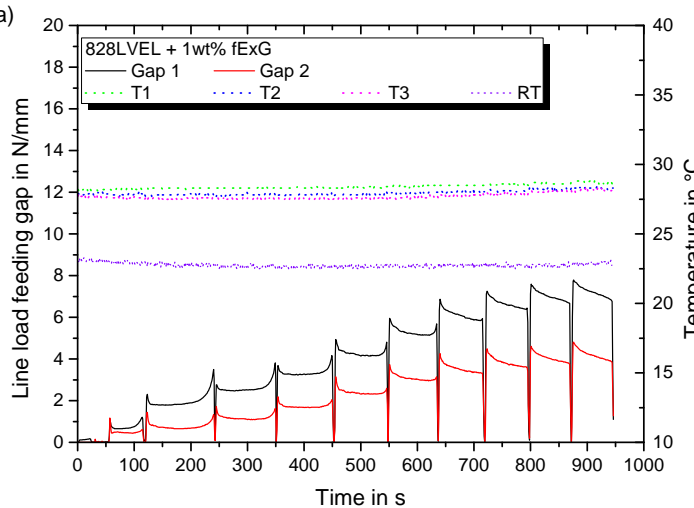

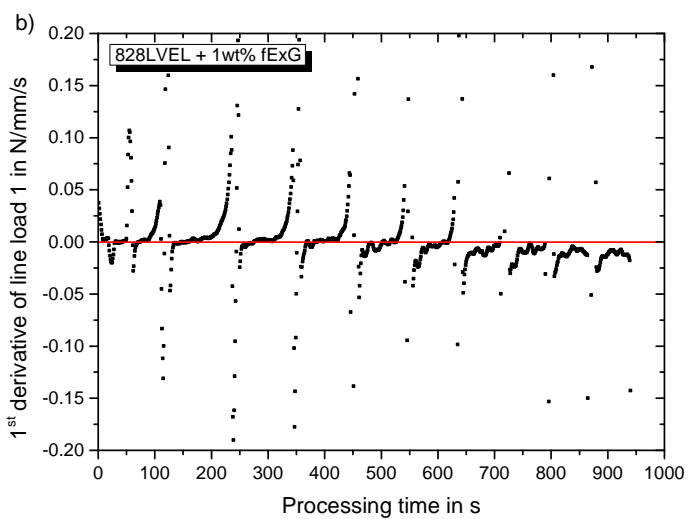

Figure 4.23: Functionalized Exfoliated Graphene dispersed in 828LVEL: a) line load and temperature development for 1 wt.\%, b) first derivative of line load in the feeding gap.

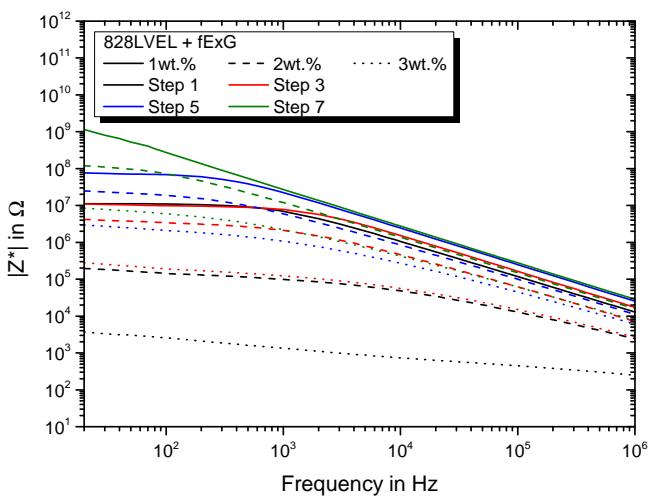

Figure 4.24: Impedance Spectra for fEG in 828LVEL.

\section{Conclusion}

Concluding, higher viscous matrices are favorable to reduce processing time. Surprisingly, a viscosity increase, due to increase of particle loading, does not significantly affect processing time, offering high potential for the design of efficient dispersion processes. The TRM dispersion process is highly reproducible, independent from used particles and machines. Continuous negative first derivation of the line load indicates the homogeneity of the dispersion. Combination of line load evaluation with impedance spectroscopy leads to very precise knowledge of dispersion state. Mild energy input through three roll mills is sufficient to spread tightly entangled SWCNT bundles to a highly conductive electrical network. It was also confirmed that graphene-like materials and precursors can be efficiently dispersed and further exfoliated during the dispersion process, whereby especially the use of electrochemically expanded graphite, stabilized in ethanol showed promising results towards the cost-effective production of graphene-epoxy composites with extreme high filler loadings, which is especially required for masterbatch production.

\section{Acknowledgements}

The authors thank the German Research Foundation (DFG, project "Multifunktionale Komposite Gedruckte Elektronik zur strukturintegrierten Zustandsüberwachung von Faser - Kunststoff - Verbun- 
den" - Projectnumber: 393868053) for financial support of this project. This project has received funding from the European Research Council (ERC) under the European Union's Horizon 2020 research and innovation programme (grant agreement number 785219 and 768930). Moreover, the authors are grateful to OCSiAl for providing the SWCNT. Special thanks go to Hexion for providing the epoxy resins.

\section{Declarations of interest}

None.

\section{References}

1. Z. Fan, S.G. Advani, Journal of Rheology 51(4), 585 (2007). DOI 10.1122/1.2736424

2. S.S. Rahatekar, K.K.K. Koziol, S.A. Butler, J.A. Elliott, M.S.P. Shaffer, M.R. Mackley, A.H. Windle, Journal of Rheology 50(5), 599 (2006). DOI 10.1122/1.2221699

3. G. TIBBETTS, M. Lake, K. Strong, B. Rice, Composites Science and Technology 67(7-8), 1709 (2007). DOI 10.1016/j. compscitech.2006.06.015

4. R. Atchudan, A. Pandurangan, J. Joo, Journal of Nanoscience and Nanotechnology 15(6), 4255 (2015). DOI 10.1166/jnn.2015 9706

5. H.P.S.A. Khalil, N.Z. Noriman, M.N. Ahmad, M.M. Ratnam, N.A.N. Fuaad, Journal of Reinforced Plastics and Composites 26(3), 305 (2007). DOI 10.1177/0731684407065066

6. R.H. Baughman, A.A. Zakhidov, W.A. de Heer, Science (New York, N.Y.) 297(5582), 787 (2002). DOI 10.1126/science. 1060928

7. L.C. Tang, Y.J. Wan, D. Yan, Y.B. Pei, L. Zhao, Y.B. Li, L.B. Wu, J.X. Jiang, G.Q. Lai, Carbon 60, 16 (2013). DOI 10.1016/j. carbon.2013.03.050

8. X. Xie, Y. Mai, X. Zhou, Materials Science and Engineering: R: Reports 49(4), 89 (2005). DOI 10.1016/j.mser. 2005.04.002. URL http://ac.els-cdn.com/S0927796X05000641/1-s2.0-S0927796X05000641-main.pdf?_tid= 6c90d682-6713-11e7-8df9-00000aab0f 26\&acdnat=1499872058_5e3b9ef8c8e6ff859adbddee773d1258

9. H. Meeuw, C. Viets, W.V. Liebig, K. Schulte, B. Fiedler, European Polymer Journal 85, 198 (2016). DOI 10.1016/j.eurpolymj. 2016.10 .027

10. K.S. Novoselov, V.I. Fal'ko, L. Colombo, P.R. Gellert, M.G. Schwab, K. Kim, Nature 490(7419), 192 (2012). DOI 10.1038/ nature 11458

11. W. Ren, H.M. Cheng, Nature nanotechnology 9(10), 726 (2014). DOI 10.1038/nnano.2014.229

12. Q. Zhang, J.Q. Huang, W.Z. Qian, Y.Y. Zhang, F. Wei, Small (Weinheim an der Bergstrasse, Germany) 9(8), 1237 (2013). DOI $10.1002 / \mathrm{smll} .201203252$

13. Inkwood Research. Global carbon nanotubes market forecast 2018-2026 (2018). URL https://www.giiresearch.com/ report/ink519825-global-carbon-nanotube-market-forecast.html

14. Graphene market size, share, analysis and forecast to 2020. URL https://www.marketwatch.com/press-release/ graphene-market-size-share-analysis-and-forecast-to-2020-2018-04-30

15. Graphene market to expand with strong cagr of $33.5 \%$ by 2023 ; companies indulging in collaborations to sustain market position. URL https://www.prnewswire.com/news-releases/graphene-market-to-expand-withstrong-cagr-of-335-by-2023-companies-indulging-in-collaborations-to-sustain-market-position680258713.html

16. N. Grobert, Materials Today 10(1-2), 28 (2007). DOI 10.1016/S1369-7021(06)71789-8

17. OCSiAl. Certification and h\&s. URL https://ocsial.com/en/certification/

18. OCSiAl. The first time ever, single wall carbon nanotubes complete reach registration. URL https://ocsial.com/en/ news/217/

19. Sixth element achieves reach registration for graphene and graphene oxide - company news - news - the sixth element (changzhou) materials technology co.,ltd. URL http://www.c6th.com/news/sixth-element-achieves-reachregistration-for-15828913.html

20. H. Meeuw, M. Radek, B. Fiedler, AIP Conference Proceedings (2018). DOI 10.15480/882.1733

21. P.C. Ma, N.A. Siddiqui, G. Marom, J.K. Kim, Composites Part A: Applied Science and Manufacturing 41(10), 1345 (2010). DOI 10.1016/j.compositesa.2010.07.003

22. A.W.K. Ma, K.M. Yearsley, F. Chinesta, M.R. Mackley, Proceedings of the Institution of Mechanical Engineers, Part N: Journal of Nanoengineering and Nanosystems 222(3), 71 (2009). DOI 10.1243/17403499JNN153

23. F.H. Gojny, M. Wichmann, U. K?pke, B. Fiedler, K. Schulte, Composites Science and Technology 64(15), 2363 (2004). DOI 10.1016/j.compscitech.2004.04.002

24. H. Yoon, M. Yamashita, S. Ata, D.N. Futaba, T. Yamada, K. Hata, Scientific reports 4, 3907 (2014). DOI 10.1038/srep03907

25. J. Texter, Current Opinion in Colloid \& Interface Science 19(2), 163 (2014). DOI 10.1016/j.cocis.2014.04.004 
26. Hauke Meeuw, Valea Kim Wisniewski and Bodo Fiedler, DOI 10.3390/polym10090999

27. Fawad Inam, Ton Peijs, In: 5th International Bhurbhan Conference on Applied Science and Technology (IBCAST 2007) Islamabad, Pakistan (8-11 January 2007)

28. H. Meeuw, J. Körbelin, D. von Bernstorff, T. Augustin, W.V. Liebig, B. Fiedler, Materialia (2018). DOI 10.1016/j.mtla.2018. 06.002

29. J. Frydel, D. Mewes, S. Luther, R.H. Schuster, KGK Kautschuk Gummi Kunststoffe 61(6), 286 (2008)

30. R. Magnier, J.-F. Agassant, P. Bastin,

31. K. Parvez, Z.S. Wu, R. Li, X. Liu, R. Graf, X. Feng, K. Müllen, Journal of the American Chemical Society 136(16), 6083 (2014). DOI $10.1021 / \mathrm{ja} 5017156$

32. C. Leopold, T. Augustin, T. Schwebler, J. Lehmann, W.V. Liebig, B. Fiedler, Journal of Colloid and Interface Science 506, 620 (2017). DOI 10.1016/j.jcis.2017.07.085

33. Y. Li, H. Zhang, M. Crespo, H. Porwal, O. Picot, G. Santagiuliana, Z. Huang, E. Barbieri, N.M. Pugno, T. Peijs, E. Bilotti, ACS Applied Materials \& Interfaces 8(36), 24112 (2016). DOI 10.1021/acsami.6b07492

34. Y. Li, H. Zhang, H. Porwal, Z. Huang, E. Bilotti, T. Peijs, Composites Part A: Applied Science and Manufacturing 95, 229 (2017)

35. K.R. Paton, E. Varrla, C. Backes, R.J. Smith, U. Khan, A. O'Neill, C. Boland, M. Lotya, O.M. Istrate, P. King, T. Higgins, S. Barwich, P. May, P. Puczkarski, I. Ahmed, M. Moebius, H. Pettersson, E. Long, J. Coelho, S.E. O’Brien, E.K. McGuire, B.M. Sanchez, G.S. Duesberg, N. McEvoy, T.J. Pennycook, C. Downing, A. Crossley, V. Nicolosi, J.N. Coleman, Nature materials 13(6), 624 (2014). DOI 10.1038/nmat3944 